\title{
Correlation transfer from basal ganglia to thalamus in Parkinson's disease
}

\author{
Pamela Reitsma*, Jonathan Rubin, Brent Doiron \\ From Nineteenth Annual Computational Neuroscience Meeting: CNS*2010 \\ San Antonio, TX, USA. 24-30 July 2010
}

\begin{abstract}
Alterations in the temporal structure of activity within the basal ganglia have been implicated in the symptoms of Parkinson's disease. Past computational work has suggested that changes in the pattern of firing of neurons in the basal ganglia, and hence in the pattern of basal ganglia inputs to thalamus, may compromise thalamocortical relay capabilities $[1,2]$. To understand how changes in basal ganglia and thalamic activity affect correlation transfer, we study a model of two thalamocortical relay neurons receiving correlated inhibitory input from basal ganglia, as well as excitatory signals. We observe that inhibitory inputs with temporal structure representative of parkinsonian conditions allow for a stronger transfer of correlation at long timescales and higher correlation susceptibility than do inputs found under normal conditions, and we analyze these changes within a reduced model framework.
\end{abstract}

Published: 20 July 2010

\section{References}

1. Rubin JE, Terman D: High frequency stimulation of the subthalamic nucleus eliminates pathological thalamic rhythmicity in a computational model. J Comput Neurosci 2004, 16:211-235.

2. Guo Y, Rubin JE, McIntyre CC, Vitek JL, Terman D: Thalamocortical relay fidelity varies across subthalamic nucleus deep brain stimulation protocols in a data-drive computational model. J Neurophysiol 2008 , 99:1477-1492.

doi:10.1186/1471-2202-11-S1-P114

Cite this article as: Reitsma et al:: Correlation transfer from basal ganglia to thalamus in Parkinson's disease. BMC Neuroscience 2010 11(Suppl 1): P114.

Submit your next manuscript to BioMed Central and take full advantage of:

- Convenient online submission

- Thorough peer review

- No space constraints or color figure charges

- Immediate publication on acceptance

- Inclusion in PubMed, CAS, Scopus and Google Scholar

- Research which is freely available for redistribution

Submit your manuscript at www.biomedcentral.com/submit 